\title{
Conhecimento matemático para ensinar Álgebra nos Anos Iniciais do Ensino Fundamental
}

\section{Mathematical knowledge for teaching algebra at early years}

\author{
Miriam Criez Nobrega Ferreira ${ }^{1}$ \\ Miguel Ribeiro ${ }^{2}$ \\ Alessandro Jacques Ribeiro ${ }^{3}$
}

\begin{abstract}
Resumo
Várias são as pesquisas, sobretudo realizadas no exterior, que evidenciam a importância do trabalho com o Pensamento Algébrico nos Anos Iniciais do Ensino Fundamental, porém elas vêm focando essencialmente o aluno e o que ele aprende, deixando o professor à margem dessa discussão. Em razão da importância, para a aprendizagem dos alunos, do conhecimento matemático para ensinar e também da potencialidade do trabalho com o Pensamento Algébrico nos Anos Iniciais, este artigo tem por objetivo debater o conhecimento matemático revelado por um grupo de professores dos Anos Iniciais, ao discutir tarefas com potencial algébrico. Os dados foram coletados no contexto de um curso de extensão de 32 horas, e os resultados evidenciam a ainda pouca familiaridade dos participantes com as questões centrais que envolvem a caracterização e o trabalho com o Pensamento Algébrico.
\end{abstract}

Palavras-chave: Álgebra nos Anos Iniciais, Pensamento Algébrico, Conhecimento matemático dos professores.

\begin{abstract}
Several researches bring to front the important of Algebraic Thinking at early years (mainly at international level). But such researches focus mainly on students and their learning, leaving aside the teachers and their knowledge. Considering, in an intertwined manner, the importance and role of teachers' knowledge in students learning and the potentialities of Algebraic Thinking at early grades, this paper aims at identify and discuss the mathematical knowledge for teaching revealed by a group of teachers when discussing tasks aimed at enhancing the Algebraic Thinking. Data has been gathered in a professional development course and the results reveal some problematic issues concerning the core aspects related with Algebraic Thinking.
\end{abstract}

Keywords: Algebra in early years; Algebraic Thinking; Mathematical Knowledge for Teaching.

\footnotetext{
${ }^{1}$ Mestre em Ensino e História das Ciências e da Matemática pela Universidade Federal do ABC (UFABC). Doutoranda em Didática da Matemática pela Universidade de Lisboa, Portugal. E-mail: criezmiriam@gmail.com

${ }^{2}$ Doutor em Educação Matemática pela Universidad de Huelva (Espanha). Professor da Faculdade de Educação da UNICAMP, Brasil. E-mail: cmribas78@gmail.com

${ }^{3}$ Doutor em Educação Matemática pela Pontifícia Universidade Católica de São Paulo (PUC/SP). Professor no Centro de Matemática, Computação e Cognição (CMCC) da Universidade Federal do ABC (UFABC), Brasil. E-mail: alessandro.ribeiro@ufabc.edu.br
} 


\section{Introdução}

Sendo o conhecimento do professor o elemento central nas aprendizagens dos alunos (Nye, Konstantopoulo \& Hedges, 2004), seria de se esperar que as pesquisas com foco no professor acompanhassem as que se dirigem aos alunos, mas isso pouco se verifica: as pesquisas com foco no professor e no seu conhecimento são mais escassas (Kieran, Pang, Schifter, \& Ng, 2016). Nessa linha, em particular, as pesquisas relacionadas com o Pensamento Algébrico têm tido também como foco essencial os alunos.

A problemática de pesquisa que aqui se aborda está justamente na confluência entre o ensino e aprendizagem de Álgebra e o conhecimento matemático do professor dos Anos Iniciais, considerando que, como afirma Ma (2009, p. 246), "a qualidade do conhecimento da matéria pelo professor afecta directamente a aprendizagem dos alunos", e existe, portanto, uma relação direta entre o conhecimento do professor - no que diz respeito tanto ao saber quanto ao saber fazer - e o sucesso escolar dos alunos.

Dentro desse cenário, neste artigo procuramos ampliar o entendimento sobre o conhecimento do professor que ensina matemática e com esse objetivo perseguimos a seguinte questão: que conhecimento matemático para ensinar revela um grupo de professores dos Anos Iniciais, quando eles discutem tarefas com potencial algébrico?

Para tanto, o artigo ${ }^{4}$ inicia-se com uma primeira seção na qual se abordam aspectos relacionados à Álgebra nos Anos Iniciais - abstraídos principalmente da literatura internacional - e a pertinência de seu ensino no início da escolarização. A segunda seção trata da formação de professores e enfatiza os aspectos que dizem respeito aos diferentes conhecimentos matemáticos envolvidos na docência, com base no quadro teórico do Mathematical Knowledge for Teaching ${ }^{5}$ (MKT), proposto por Ball, Thames e Phelps (2008). Posteriormente são apresentados o contexto e a metodologia da pesquisa e, em uma última seção, a análise dos dados, enfatizando a discussão acerca do trabalho com o Pensamento Algébrico e o MKT. Terminamos com a discussão dos resultados, elencando algumas potencialidades e implicações para a prática docente e para a formação.

\section{O ensino da Álgebra nos Anos Iniciais e sua problemática}

Muito se tem escrito sobre as dificuldades apresentadas por alunos na aprendizagem da Matemática (e.g., Lins \& Gimenez, 2001). Igualmente, muitas pesquisas têm se debruçado sobre a Matemática e seu ensino e sobre a forma como este pode estar produzindo e solidificando déficits na aprendizagem, ao adotar uma forma de trabalhar os conteúdos matemáticos sedimentada na utilização de livros didáticos, seguindo o ritual da explicação e

\footnotetext{
${ }^{4}$ Esse artigo é parte integrante de uma dissertação de mestrado (Ferreira, 2017a), desenvolvida no formato multipaper e que investiga a Álgebra nos Anos Iniciais e a Formação do Professor de Matemática.

${ }^{5}$ Optamos por usar a nomenclatura em inglês por esta ser reconhecida internacionalmente e por receio de que a tradução desvirtue alguns dos aspetos associados a esta conceitualização.
} 
do exercício, muitas vezes sem o aprofundamento conceitual necessário (e.g., Amaral, Ribeiro, \& Godoy, 2014).

Um dos eixos matemáticos nos quais esta dificuldade se faz acentuada relaciona-se à aprendizagem de Álgebra e Funções (Cai \& Knuth, 2011; Molina, 2009). Pesquisas realizadas nas últimas décadas do século XX (e.g., Kieran, 1992; Linchevski, 1995) apontaram que alunos entre 12 e 15 anos apresentaram deficiências no que se refere à aprendizagem tanto da Aritmética quanto da Álgebra. As dificuldades na passagem da Aritmética para a Álgebra impulsionaram pesquisas acerca do Pensamento Algébrico na perspectiva do trabalho com alunos mais novos, para promover uma transição mais suave para o estudo formal da Álgebra (Kieran et al., 2016).

Neste sentido, o foco mais recente tem vindo a debruçar-se na possibilidade, na viabilidade e nas formas de abordar aspectos da Álgebra já nos Anos Iniciais do Ensino Fundamental e na Educação Infantil. Os estudos de Blanton e Kaput (2004) realizados com alunos desde a Educação Infantil até ao 5. ${ }^{\circ}$ ano de escolaridade mostraram que os alunos mais jovens, além de trabalhar com as propriedades dos números e operações, já têm capacidade de se envolver no denominado pensamento covariacional e podem descrever como as quantidades se correlacionam. Da mesma forma, outros estudos (e.g., Mestre \& Oliveira, 2011; Russel, Schifter, \& Bastable, 2011) têm demonstrado que os alunos já têm condições de pensar de forma algébrica desde pequenos. Por exemplo, Mestre e Oliveira (2011, p. 201) referem que:

as recentes tendências internacionais ...consideram que a introdução ao pensamento algébrico deve começar nos primeiros anos, mas que este não deve constituir um tema adicional do currículo. Ao invés, deve ser entendido como uma forma de pensamento que aporta significado, profundidade e coerência à aprendizagem de outros temas.

No cenário brasileiro, conforme apontado por Ferreira (2017b), os documentos curriculares nacionais mais recentes já apontam para um trabalho com o Pensamento Algébrico, notadamente os relativos ao Pacto Nacional pela Alfabetização na Idade Certa (PNAIC) e a Base Nacional Comum Curricular (BNCC). Ainda que a BNCC não seja um documento definitivo por não ter sido aprovado, apresenta a Álgebra como uma das unidades temáticas da Matemática voltada para os Anos Iniciais do Ensino Fundamental.

Ao pensarmos em Álgebra dos Anos Iniciais, é essencial situar e contextualizar a que nos referimos, sendo necessária, portanto, uma discussão associada ao denominado Pensamento Algébrico. Para o efeito, um ponto de partida corresponde à discussão da relação entre Álgebra e Aritmética e à configuração do Pensamento Algébrico.

Para Carraher, Schliemann, Brizuela e Earnest (2006) ficou evidenciada, na História da Matemática, uma clara demarcação entre Aritmética e Álgebra, resultando em uma tensão entre elas. Essa diferenciação também é sentida, ainda, no currículo escolar e em documentos oficiais (e.g., Brasil, 1997), uma vez que tradicionalmente os conteúdos matemáticos são dispostos ao longo da escolaridade, de forma a se iniciar por aqueles referentes à Aritmética (e.g., o trabalho com o sistema de numeração decimal e as quatro operações básicas), para 
somente em seguida discorrer sobre elementos com abordagens da Álgebra (e.g., sequências, padrões, generalizações).

Alguns autores vêm questionando essa separação entre Álgebra e Aritmética (e.g., Canavarro, 2007; Lins \& Gimenez, 2001; Russell et al., 2011), argumentando que os alunos não necessitam aprender primeiramente Aritmética para só depois aprender Álgebra, pois existe uma relação intrínseca entre esses dois âmbitos da Matemática.

Uma integração entre essas duas áreas pode, assim, colaborar para uma maior compreensão, por parte do aluno e do professor, da estrutura que sustenta essa área de ensino (e.g., Blanton \& Kaput, 2005; Canavarro, 2007; Carraher et al., 2006; Kieran, 2004; Schliemann, Carraher, \& Brizuela, 2007), tal como refere Canavarro (2007, p. 89):

É a partir da estrutura da Aritmética que se podem construir os aspectos sintáticos da Álgebra, o que implica analisar as expressões aritméticas não em termos do valor numérico obtido através do cálculo, mas em termos da sua forma (por exemplo, concluir que $33+8=8+33$ não porque ambos constituem 41 , mas porque na adição a ordem das parcelas é indiferente).

Como apontado por Ponte, Branco e Matos (2009), o grande objetivo do estudo da Álgebra no Ensino Fundamental e Médio é "desenvolver o Pensamento Algébrico nos alunos" (Ponte et al. 2009, p. 10). É também nessa linha que, ao nos referirmos ao trabalho com Álgebra nos primeiros anos do Ensino Fundamental, aprofundamos a discussão do significado do Pensamento Algébrico.

Tal como em muitos outros domínios, inexiste uma visão única na comunidade de educadores matemáticos com respeito ao que significa o Pensamento Algébrico e o pensar algebricamente.

Blanton e Kaput (2005, p. 413) definem o Pensamento Algébrico como "um processo no qual os alunos generalizam ideias matemáticas de um conjunto particular de exemplos, estabelecem generalizações por meio do discurso de argumentação, e expressam-nas, cada vez mais, em caminhos formais e apropriados à sua idade". Consideram quatro formas de Pensamento Algébrico: o uso da aritmética como o domínio da expressão e a formalização da generalização (Aritmética Generalizada); a generalização de padrões numéricos para descrever as relações funcionais (Pensamento Funcional); a modelação como um domínio para a expressão e a formalização das generalizações; e a generalização sobre sistemas matemáticos abstratos do cálculo e das relações (Blanton \& Kaput, 2005).

Focando a atenção no sinal de igual (um dos elementos que compõem o Pensamento Algébrico), Ponte et al. (2009) referem três significados que ele pode assumir: com sentido operacional (que corresponde à busca do resultado); como sinal de equivalência (marcado pela equivalência entre o que "está antes" e o que "está depois"); para definir uma relação funcional (como, por exemplo, em $y=3 x+5$ ). Neste nosso trabalho, o sinal de igual e os seus diferentes significados passam a ter uma especial importância, na medida em que nos Anos 
Iniciais o sentido operacional é amplamente utilizado, em detrimento dos outros significados (Trivilin \& Ribeiro, 2015).

O conhecimento das propriedades das operações tem fundamental importância quando o que se deseja é um trabalho que contribua para o desenvolvimento do Pensamento Algébrico, uma vez que "a identificação destas propriedades e a sua generalização desde os primeiros anos de escolaridade constituem uma base importante para o pensamento algébrico" (Ponte et al., 2009, p. 28).

Nessa mesma linha, Wasserman (2016) aponta que, quando ensinam Matemática, os professores precisam reconhecer as propriedades das operações, a forma como elas surgem em sala de aula tanto explícita como implicitamente (e.g., as múltiplas formas em que os alunos muitas vezes recorrem a elas no "cálculo mental" ou "cálculo com a cabeça"); e precisam saber também como problematizá-las.

Um componente essencial no trabalho focando o desenvolvimento do Pensamento Algébrico nos Anos Iniciais do Ensino Fundamental prende-se ao papel desempenhado pela generalização, a qual, a partir de um conjunto particular de dados, permite chegar a uma regularidade matemática. Essa centralidade da generalização é sintetizada por Schliemann et al. (2007, p. 12), ao afirmarem que "a generalização está no coração do pensamento algébrico".

Uma vez que nossa investigação apresenta dados coletados a partir de um curso de formação continuada cujas tarefas carregam um potencial algébrico (veja-se a próxima seção), é importante assinalar o que afirmam Fiorentini, Fernandes e Cristóvão (2005): por um lado, por ser o pensamento uma ação cognitiva do sujeito, cabe a este, ao se deparar com uma tarefa de sala de aula, utilizar ou não um pensamento algébrico, a depender, em certa medida, de suas ferramentas cognitivas. Por isso não existem tarefas específicas para o desenvolvimento do Pensamento Algébrico. Por outro lado, existem tarefas que podem colaborar para o desenvolvimento desse pensamento, bem como intervenções didáticas do professor, necessárias para estimular esse tipo de pensamento (Ferreira, Ribeiro \& Ribeiro, 2017, no prelo).

Diante do apresentado, alguns aspectos surgem como elementos constituintes do presente trabalho e farão parte da análise dos dados ancorados na viabilidade do trabalho com o Pensamento Algébrico nos Anos Iniciais: a generalização e a busca pelas regularidades como aspecto central desse tipo de pensamento (Mason, Graham, \& Johnston-Wilder, 2005), a Aritmética Generalizada pressupondo o trabalho com as propriedades das operações (Blanton \& Kaput, 2005) e os diferentes significados do sinal de igual (Trivilin \& Ribeiro, 2015). 


\section{Conhecimento matemático para ensinar nos Anos Iniciais do Ensino Fundamental}

Para que se possa almejar desenvolver um Pensamento Algébrico com os alunos e nos alunos, torna-se essencial que o próprio professor detenha o conhecimento desse pensamento e sobre ele. Dentre uma diversidade de fatores (e.g., contexto sociocultural e econômico, por exemplo), o conhecimento do professor é aquele que maior influência tem nos resultados (e nas aprendizagens) dos alunos (Nye et al., 2004). Nesse sentido, e tendo em consideração a necessidade de que aos alunos sejam propiciadas oportunidades de aprendizagem que permitam o desenvolvimento do Pensamento Algébrico, torna-se essencial um mais amplo entendimento sobre o conteúdo do conhecimento do professor nessa temática, de modo a possibilitar, posteriormente, equacionar formas de melhorar a prática, as aprendizagens dos alunos e a própria formação de professores.

Ao falarmos do conhecimento do professor que ensina Matemática, este pode ser considerado sob uma multiplicidade de perspectivas e conceptualizações. Muitas dessas conceptualizações têm por base as ideias de Shulman (1986) e buscam concretizar alguns aspetos do conhecimento do professor. No que se refere, em particular, ao conhecimento do professor que ensina Matemática, uma abordagem considera os subdomínios nos dois domínios do conhecimento do professor considerados por Shulman como aqueles que se relacionam com a especificidade do conteúdo a abordar: Subject Matter Knowledge ${ }^{6}$ (SMK) e Pedagogical Content Knowledge ${ }^{7}$ (PCK). Dentre essas diversas conceptualizações (e.g., Knowledge Quarted - Rowland, Huckstep, \& Thwaites, 2005; Mathematic Teachers Specialized Knowledge - Carrillo, Climent, Contreras \& Muñoz-Catalán, 2013; Mathematical Knowledge for Teaching - Ball et al., 2008), no âmbito deste texto, consideramos a conceptualização do Mathematical Knowledge for Teaching - MKT (Ball et al., 2008). Essa conceptualização emergiu a partir da análise da prática, e os subdomínios considerados são tomados como um bom ponto de partida para pensar em tarefas para a formação de professores (e.g., Jakobsen, Thames, \& Ribeiro, 2013).

Tendo em consideração o foco e o contexto do estudo que aqui apresentamos, centramos nossa atenção em dois dos subdomínios do SMK (CCK e SCK) e também em dois dos subdomínios do $\mathrm{PCK}^{8}$ (KCS e KCT), considerando ainda que o desenvolvimento do PCK se sustenta no SMK (Krauss, Baumert \& Blum, 2008; Jakobsen, Ribeiro, \& Mellone, 2014).

\footnotetext{
${ }^{6}$ Conhecimento do Conteúdo.

${ }^{7}$ Conhecimento Pedagógico do Conteúdo.

8 Os seis subdomínios includidos no MKT são: Common Content Knowledge (CCK); Specialized Content Knowledge (SCK) e Horizon Content Knowledge (HCK) no SMK; e Knowledge of Content and Teaching (KCT), Knowledge of Content and Students (KCS) e Curricular Knowledge (CK), como parte do PCK. Também aspetos do Horizon Content Knowledge se encontram associados ao KCS (Jakobsen et al., 2013), mas, por motivos de delimitação do estudo, eles não serão aqui discutidos.
} 
DOI: http://dx.doi.org/10.20396/zet.v25i3.8648585

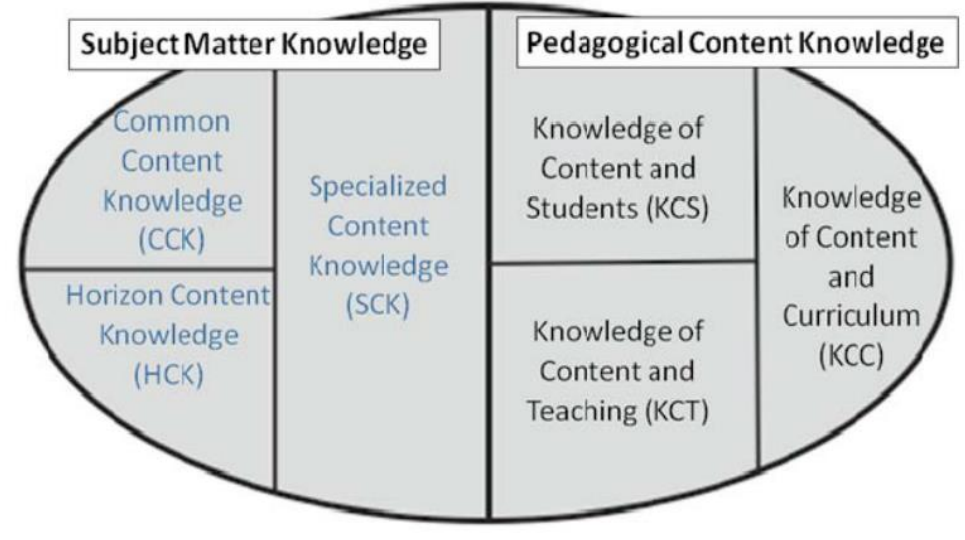

Figura 1 - Conhecimento matemático para ensinar Fonte: Ball et al. (2008, p. 403).

Assim, ao professor que pretende que os seus alunos entendam o que fazem, por que o fazem e como o fazem, a cada momento, compete um conhecimento do conteúdo muito próprio, pois, para além de um saber fazer (Common Content Knowledge - CCK) ${ }^{9}$ que lhes permita resolver as tarefas/problemas que facultam aos seus alunos, devem possuir também um conhecimento que sustente, por exemplo, entender os porquês matemáticos associados a cada um dos passos de resolução dessas tarefas/problemas. Considerando o contexto do Pensamento Algébrico, não é, portanto, suficiente saber/obter o resultado correto de determinada operação ou identificar uma solução como incorreta, pois é necessário também um conhecimento especializado do conteúdo que é específico do professor (para o trabalho docente). Esse conhecimento associa-se a um saber matemático relacionado com, entre outros, um entendimento dos porquês matemáticos ou dos motivos matemáticos que sustentam uma resposta incorreta. O Specialized Content Knowledge (SCK) corresponde a um conhecimento matemático necessário apenas ao professor que pretende que o outro entenda verdadeiramente o que faz e não o execute meramente como um conjunto de procedimentos sem sentido. Não se esgota, no entanto, no conhecimento relativo aos procedimentos (entender os porquês), em um sentido mais lato, pois envolve também os necessários conceitos. Ao professor cumpre conhecer também como diferentes imagens, exemplos, contraexemplos e não exemplos do conceito podem fazer com que se adquira uma noção ampla dele e das suas relações com outros conceitos.

A diferença entre o CCK e o SCK poderá ser encarada como saber fazer e saber os porquês matemáticos associados ao que se faz (e por que se faz de determinada forma). Assim, por exemplo, no contexto das equações, mais do que saber apenas determinar o resultado (qual o valor de $\mathrm{x}$ - considerado CCK), será essencial que o professor possua um conhecimento que lhe permita entender e identificar não apenas o erro - que qualquer

9 Este CCK corresponde a um conhecimento adquirido por escolarização, no sentido tradicional, ou seja, nas disciplinas de matemática, e é comum a qualquer indivíduo com alguma formação matemática de nível superior/universitário (e.g., economistas, engenheiros, enfermeiros). 
indivíduo apto a resolver a equação faz -, mas essencialmente a sua fonte, associada à compreensão dos motivos que levam à ocorrência desse erro. Uma vez que os motivos que sustentam essas respostas lhe são alheios, sua compreensão torna o trabalho de ensinar muito mais complexo (SCK) e exigente (Ribeiro, Mellone, \& Jakobsen, 2016). Ao professor cumprirá também conhecer processos alternativos de apresentação/resolução dos conteúdos para que, sem dificuldade, possa colmatar as lacunas de aprendizagem.

Esses subdomínios do conhecimento matemático do professor permitem uma articulação entre conhecer o que os alunos sabem ou não e o conhecimento matemático (Knowledge of Content and Students - KCS). Portanto, os professores necessitam antecipar o que os alunos pensam, quais as dificuldades que podem sentir, as suas motivações, ou seja, situações que exigem interação entre a compreensão matemática e o conhecimento do pensamento matemático dos seus alunos. Por exemplo, não é incomum que os estudantes, no início do processo de representação numérica, ao serem solicitados a representar o numeral 23, escrevam 203. Cabe ao professor ter conhecimento de que esse tipo de equívoco ocorre, possivelmente, em virtude da estrutura da língua portuguesa, que na pronúncia dos números segue o padrão aditivo, ou seja, vinte $e$ um, vinte $e$ dois, vinte $e$ três.

\section{Contexto e Metodologia}

O presente texto é parte de um trabalho de dissertação ${ }^{10}$, cuja pesquisa é de natureza qualitativa e de cunho interpretativo, e tem por objetivo investigar o conhecimento matemático para o ensino do Pensamento Algébrico nos Anos Iniciais do Ensino Fundamental. Realizada no contexto de uma Formação Continuada ${ }^{11}$ envolvendo professores dos Anos Iniciais, a pesquisa almeja contribuir para o desenvolvimento do Pensamento Algébrico dos participantes. O foco dessa formação envolveu a discussão de características do trabalho com as propriedades dos números e das operações; o sinal de igualdade como equivalência; sequências e padrões, enfatizando os elementos que compõem a Aritmética Generalizada e o Pensamento Funcional (Blanton \& Kaput, 2005).

Os dados que aqui serão discutidos foram coletados no segundo encontro da formação, a partir das tarefas realizadas com 14 professores participantes do curso, e dizem respeito às suas respostas escritas e às gravações de áudio e vídeo. Durante o curso os participantes desenvolveram o seu trabalho em 4 grupos, de 3 ou 4 professores. Neste texto

\footnotetext{
10 A dissertação tem como título Álgebra nos Anos Iniciais do Ensino Fundamental: uma análise do conhecimento matemático acerca do Pensamento Algébrico e foi desenvolvida no formato multipaper, tendo em sua composição outros dois artigos ("Álgebra nos Anos Iniciais do Ensino Fundamental: uma análise dos documentos curriculares nacionais"; "Álgebra nos Anos Iniciais do Ensino Fundamental: investigando a compreensão dos professores acerca do Pensamento Algébrico"), que contemplam outros objetivos específicos da referida pesquisa.

11 O curso foi dinamizado pela primeira autora, teve uma carga horária de 32 horas (20 horas presenciais e 12 horas a distância) e ocorreu no contexto do Programa Observatório da Educação - Obeduc -, projeto "Conhecimento Matemático para o ensino de Álgebra: uma abordagem baseada em perfis conceituais" que tem a sua sede na Universidade Federal do ABC.
} 
debruçamo-nos sobre uma tarefa composta por duas partes e voltada para alunos dos Anos Iniciais, selecionada entre as atividades propostas e discutidas na formação. $\mathrm{Na}$ primeira parte, com o intuito de discutir posteriormente as propriedades das operações, foram fornecidas 4 expressões numéricas que os professores deveriam assinalar como verdadeiras ou falsas, justificando suas escolhas (Figura 2).

\begin{tabular}{|c|c|c|c|}
\cline { 2 - 4 } \multicolumn{1}{c|}{} & V & F & Justificativa \\
\hline $\mathbf{2 4}+\mathbf{3 7}=\mathbf{3 7}+\mathbf{2 4}$ & & & \\
\hline$\diamond \mathbf{2 7}-\mathbf{2 7}=\mathbf{2 7}$ & & & \\
\hline$\square \mathbf{x}=\diamond$ & & & \\
\hline$\square+0=\square$ & & & \\
\hline
\end{tabular}

Figura 2 - Tarefa matemática Parte 1

Fonte: Adaptado de Mestre \& Oliveira (2011)

A escolha desta tarefa se associa ao fato de as expressões selecionadas terem em sua base as propriedades das operações - aspecto da Matemática que se refere à Aritmética Generalizada: a primeira tinha por base a propriedade comutativa; a segunda, a propriedade associativa; a terceira, o elemento neutro da multiplicação; e a última, o elemento neutro da adição. Considerando que apenas assinalar verdadeiro ou falso pouco contribuiria para subsidiar o trabalho com foco em aprofundar o entendimento do conteúdo do MKT do professor dos Anos Iniciais, optamos por solicitar justificativas que propiciassem mais elementos para compreender a manifestação deste conhecimento do professor.

$\mathrm{Na}$ segunda parte da tarefa (Figura 3) foram fornecidas respostas de alunos de uma turma de quinto ano do Ensino Fundamental à mesma questão, com o objetivo de que os professores atribuíssem sentido a elas (Jakobsen et al., 2014), de forma a poderem contestar as três questões colocadas.

As respostas incluídas nessa segunda etapa foram selecionadas de entre uma diversidade de respostas, considerando que deveriam permitir discutir vários aspetos do Pensamento Algébrico.

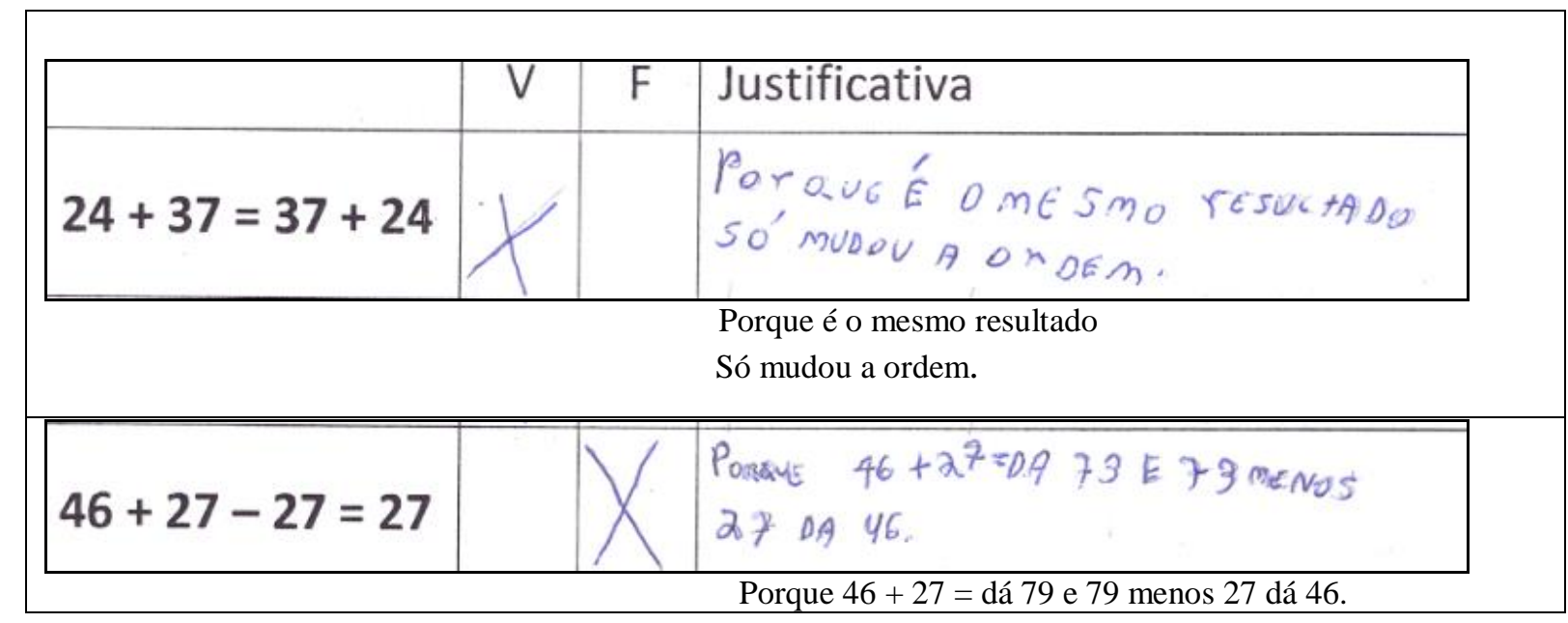


DOI: http://dx.doi.org/10.20396/zet.v25i3.8648585

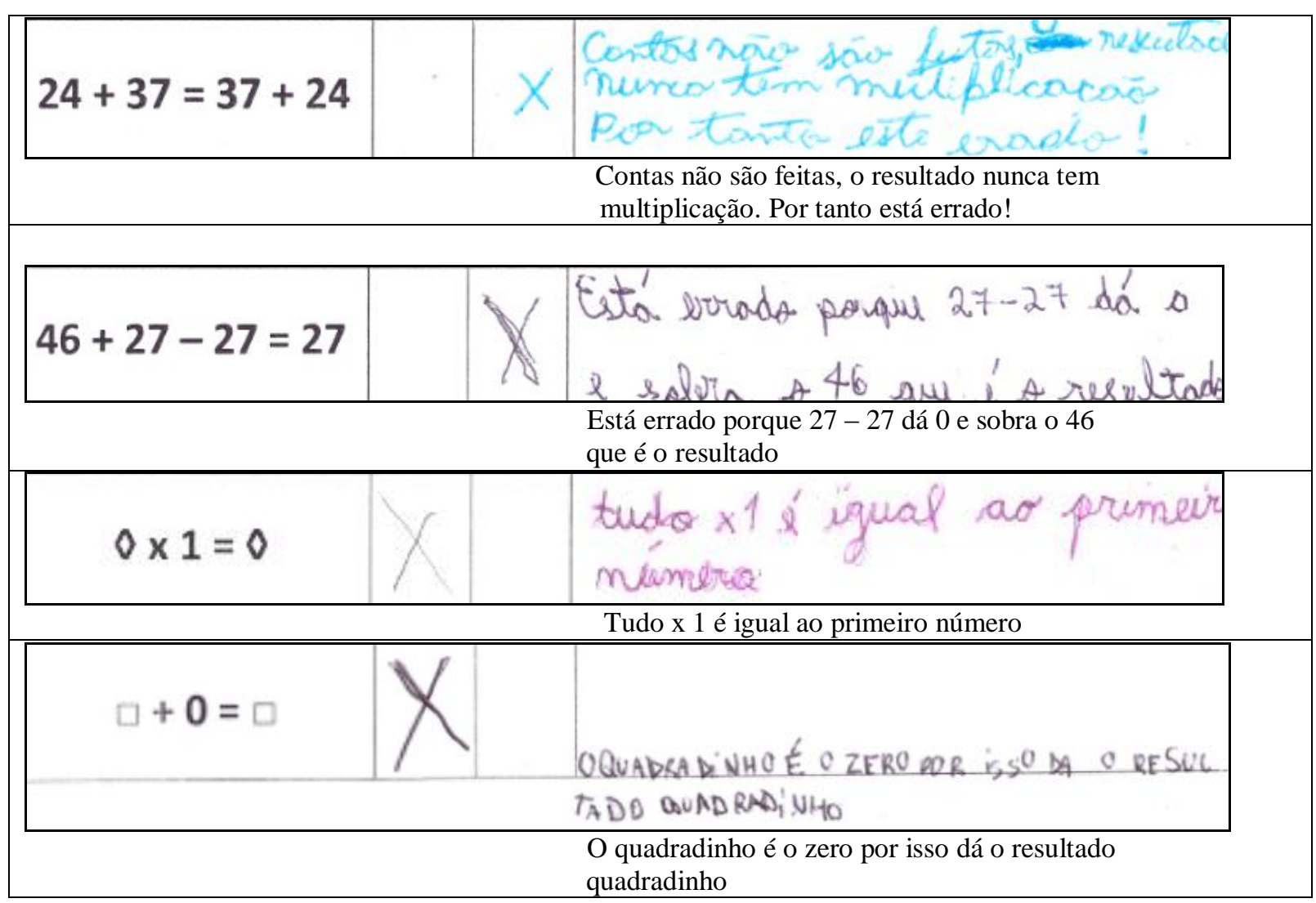

1 - Quais conteúdos, conceitos matemáticos estão presentes nas questões respondidas pelos alunos?

2 - Qual a coerência da justificativa dos alunos, tendo por base os conceitos matemáticos envolvidos?

3 - Para cada resposta dos alunos, que intervenções você faria de forma a propiciar uma reflexão mais aprofundada da questão?

Figura 3 - Tarefa matemática Parte 2

Fonte: elaborado pela primeira autora

Assim, a análise centrou-se, na primeira parte, em identificar as diferentes argumentações que os professores apresentam, ao contestar uma tarefa preparada para os seus alunos (acedendo, assim, ao que se pode considerar incluído em um CCK elementar). Na segunda parte da tarefa o foco foi a identificação de evidências do SCK e do KCS durante as discussões nos pequenos grupos e também na discussão em grande grupo.

Expressas as opções metodológicas, apresentamos aqui a análise dos dados, que primeiramente versará sobre a primeira atividade, na qual os professores responderam à tarefa (para si próprios, e individualmente), e em seguida a análise da discussão realizada pelos professores, sustentada nas respostas dos alunos.

\section{Análise e discussão}


Relativamente à primeira parte da tarefa (responder à questão colocada aos alunos), todos os participantes apresentaram justificativas com base nas propriedades das operações, mas sem nomeá-las explicitamente, tendo ocorrido a utilização de uma linguagem matemática menos adequada (e.g., troca de nomenclatura de "parcela" por "fator" e "resultado" por "produto").

Apenas um dos grupos recorreu ao cálculo como forma de evidenciar a igualdade da expressão $46+27-27=27$, mas não justificou por que podemos considerar o sinal de igual com significado operacional: "fazendo o cálculo não dá este resultado". Assumir o sinal de igual como um elemento operacional (e não como equivalência) configura-se como um dos elementos que conduzem a dificuldades na posterior aprendizagem de aspetos algébricos, já que esse significado é "fundamental para o desenvolvimento de equação, conceito central na Álgebra do Ensino Fundamental II" (Silva \& Ribeiro, 2014, p.80). No exemplo - segunda resposta incluída -, em particular, a justificativa não necessita sustentar-se no resultado das operações, já que, para concluir a falsidade da expressão, é "suficiente" conhecer e saber usar a propriedade associativa.

Foi na segunda parte da tarefa, em que os professores teriam de atribuir sentido às produções dos alunos (Jakobsen et al., 2014) e discutir as três questões propostas, que emergiram mais evidências de conhecimento dos participantes, o que reforçou também o papel e a importância das resoluções selecionadas. Essa era já a situação esperada, pois a primeira parte da tarefa é voltada a alunos do Ensino Fundamental.

A passagem contida na Figura 4 revela alguns aspetos do conhecimento dos professores, ao discutirem uma das produções dos alunos:

P1 - "Tudo vezes um é igual ao primeiro número" (a professora leu o que o aluno escreveu na justificativa da questão).

$\mathrm{P} 2$ - Ai ele já sabe as propriedades...

P1 - Ele entendeu a propriedade da multiplicação, só não entende a ordem ainda, porque não é necessariamente o primeiro número, porque, se o número um estivesse aqui (onde está o balão) e o zero (o balão) aqui (onde está o número um), a resposta seria a mesma...

$\mathrm{P} 2-\operatorname{Sim} . .$.

$\mathrm{P} 1$ - Então ... por que ele não entende que o inverso da conta...

$\mathrm{P} 2$ - Ou talvez ele até entenda, mas como a conta está desta forma...

$\mathrm{P} 1$ - Se limitou a essa explicação.

P2 - Exatamente! Para saber disso (se o aluno entende que para a propriedade do elemento neutro da multiplicação não importa a ordem dos fatores) você teria que dar outro exemplo.

P1 - Para ver como ele responderia...

Figura 4 - Discussão sobre as propriedades

Fonte: Protocolo de pesquisa

Essa discussão revela um conhecimento comum do conteúdo matemático (CCK), quando as professoras detectam a propriedade do elemento neutro da multiplicação, ainda que sem nomeá-la, tomando-a não como uma das propriedades da multiplicação, mas como "a propriedade da multiplicação". Também levantam a discussão acerca da propriedade Zetetiké, Campinas, SP, v.25, n. 3, set./dez.2017, p.496-514

ISSN 2176-1744 
DOI: http://dx.doi.org/10.20396/zet.v25i3.8648585

comutativa, uma vez que identificam que nessa propriedade a ordem dos fatores não importa. É relevante que os professores consigam enxergar nas operações as suas propriedades, ou seja, o que pode ou não ser generalizável, uma vez que são elas (as propriedades) que descrevem como as operações se comportam (Blanton, Levi, Crites, Dougherty, \& Zbiek, 2011) e que permitem atribuir sentido ao que se faz e por que se faz (pode fazer ou não) a cada momento, ao utilizar os algoritmos.

Durante essa discussão identificamos também traços do conhecimento do conteúdo e dos estudantes (KCS), quando as professoras afirmam que será necessário fazer outras atividades para entender o conhecimento que o aluno revela acerca da propriedade do elemento neutro da multiplicação, pois, embora o aluno tenha argumentado que "tudo vezes um é igual ao primeiro número", essa afirmação não quer dizer que ele conheça que a inversão dos fatores não modifica o resultado (propriedade comutativa) - a própria formulação e a estrutura linguística do comentário do aluno indiciam uma ordem predeterminada no produto, para que o resultado seja a quantidade diferente da unidade.

Um dos grupos, ao refletir sobre uma das outras respostas dos alunos (Figura 5), se deteve na discussão acerca do significado do sinal de igual:

\begin{tabular}{|c|c|c|c|}
\hline & V & $\mathrm{F}$ & Justificativa \\
\hline $24+37=37+24$ & & $\lambda$ & 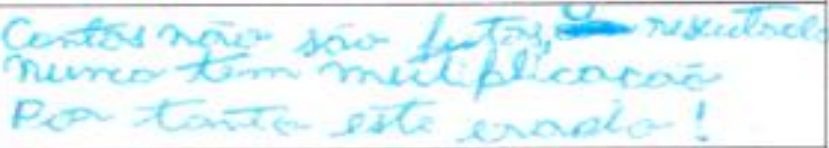 \\
\hline
\end{tabular}

$\mathrm{P} 2$ - Então o resultado para ele..., o resultado não tem que ter isso aqui (apontando para o 37 +24), o resultado tem que acabar aqui (apontando para o número 37).

$\mathrm{P} 1$ - É verdade!

$\mathrm{P} 2$ - O resultado nunca tem multiplicação, ou não tem adição, portanto, tá errado...

$\mathrm{P} 2$ - No sentido de que depois do igual é só um número.

$\mathrm{P} 1$ - E aí, como é uma expressão, ele confundiu.

$\mathrm{P} 2$ - Aí, como tem dois (dois números depois do igual), tá errado. Como pode ter dois?

$\mathrm{P} 1-E$ É isso mesmo!

$\mathrm{P} 2$ - Não é isso?

P1 - Como que o resultado pode ser outra conta? Né? Nossa, que judiação! Que nó na cabeça dessa criança! Que professora má rsrsrsrs.... É verdade!

P2 - Mas na verdade o resultado... quando a gente fala o resultado é esse aqui (apontando para o trinta e sete).

P1 - Na verdade ... a gente que ensina, né...o resultado é só aquele. E na hora de fazer ele se confundiu, coitado...

Figura 5 - Debate sobre o significado do sinal de igual

Fonte: Protocolo de pesquisa

Essa discussão envolvendo três professoras do grupo (uma não se pronunciou, apenas ouviu a discussão das colegas), analisando a justificativa fornecida por um aluno para ter considerada falsa a expressão $24+37=37+24$, evidencia alguns aspectos do conhecimento docente. As professoras identificam que os alunos se confundiram ao colocarem para o sinal 
de adição a nomenclatura da multiplicação - saber identificar o erro (CCK) - e, complementarmente, demonstram um conhecimento especializado do conteúdo (SCK) e do conteúdo e dos estudantes (KCS) - em particular P2, quando afirma que para o aluno, depois do sinal de igual, só pode aparecer um número e não outra conta, enfatizando que esse sinal tem um significado apenas operacional.

Complementarmente a essas evidências de conhecimento, essa discussão possibilitou também promover uma tomada de consciência que sustenta o desenvolvimento de um conhecimento especializado do professor (Jakobsen et al., 2014) sobre a própria prática, ainda que situada na "prática" de outrem:

P1 - Como que o resultado pode ser outra conta? Né? Nossa, que judiação...Que nó na cabeça dessa criança! Que professora má rsrsrsrs.... É verdade!

Figura 6 - Tomada de consciência da prática

Fonte: Protocolo da pesquisa

O primeiro passo de qualquer atribuição de significado a respostas dos outros se refere a uma efetiva compreensão do que esses dizem/fazem (Jakobsen et al., 2014), o que corresponde, em si, a um processo de resolução de problemas. Essa discussão na atribuição de significado às produções de outros se sustenta no conhecimento matemático do próprio professor (conteúdo, natureza, tipo), conhecimento esse que lhe permite, entre outras constatações, não apenas identificar o erro, mas, essencialmente, entender as suas possíveis origens e os porquês matemáticos que os podem sustentar; e lhe possibilita antecipar as dificuldades/facilidades dos alunos (KCS) e preparar tarefas para as colmatar, desenvolvendo o conhecimento e as capacidades matemáticas dos alunos.

A discussão ocorrida mostra que as professoras, ao discutir com seus pares, "descobrem" que os alunos não consideram o sinal de igualdade numa perspectiva de equivalência, elemento caracterizador do Pensamento Algébrico presente na Aritmética Generalizada, conforme apontado por Blanton e Kaput (2005). Esta situação traz também para a ribalta, embora de forma indireta, o papel e a importância da formação (inicial ou continuada) para propiciar discussão e reflexão, tendo por base situações da prática (aqui, respostas de alunos) para a tomada de consciência, pelo professor, do seu próprio conhecimento matemático para ensinar - mesmo que as discussões desse conhecimento não ocorram de forma explícita, o que poderia ser contraproducente.

Outro aspecto relacionado ao conhecimento matemático do professor inclui um saber associado não somente à identificação do erro do aluno (CCK), mas também e essencialmente, ao reconhecimento da natureza desse erro (SCK) para poder, no seguimento, conceituar uma exploração associada a objetivos matemáticos, propor tarefas que possibilitem o efetivo desenvolvimento do conhecimento dos alunos, objetivando, com o auxílio do que eles já conhecem, superar as suas dificuldades (antecipadas pelo professor KCS). Assim, se, por um lado, as professoras identificam o erro do aluno ao confundir o sinal de adição e a nomenclatura da multiplicação, por outro lado, elas demonstram conhecer aspectos do conhecimento e do pensamento dos alunos.

Zetetiké, Campinas, SP, v.25, n. 3, set./dez.2017, p.496-514

ISSN 2176-1744 
DOI: http://dx.doi.org/10.20396/zet.v25i3.8648585

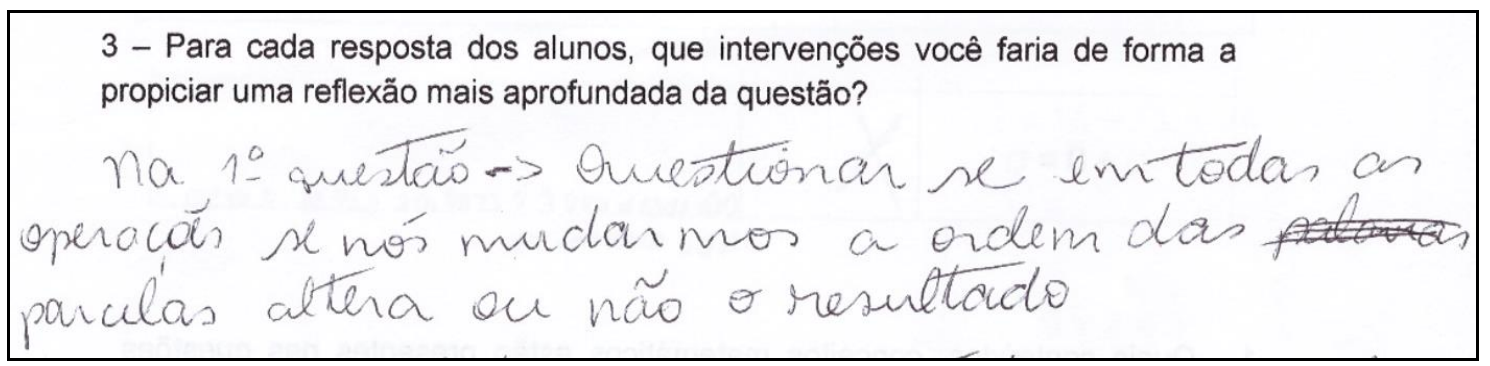

Figura 7 - Aspectos associados às intervenções

Fonte: Protocolo de pesquisa

Ao equacionarem que intervenção efetuar para cada uma das respostas dos alunos à primeira expressão $(24+37=37+24)$, os professores dirigiram sua intervenção para levar os alunos a perceberem se a propriedade que pertencia à adição (comutativa) poderia se ajustar às outras operações - se a mudança de ordem das parcelas (comutativa) poderia ocorrer com o mesmo sentido em outras operações. Essa resposta se sustenta em concepção didática que se associa a uma ação na qual se vai além da simples investigação de como o aluno chegou àquela determinada conclusão: o professor pergunta se o que funciona para a adição e para a multiplicação funcionaria também para as respectivas operações inversas, subtração e divisão, considerando que o desenvolvimento do Pensamento Algébrico pressupõe a promoção das generalizações, que, por sua vez, é derivada das propriedades das operações.

Um outro grupo (Figura 8) assumiu como elemento central da sua intervenção saber do aluno qual o caminho percorrido até aquela conclusão e, a partir daí, trabalhar com os conceitos envolvidos - nesse caso, a propriedade comutativa.

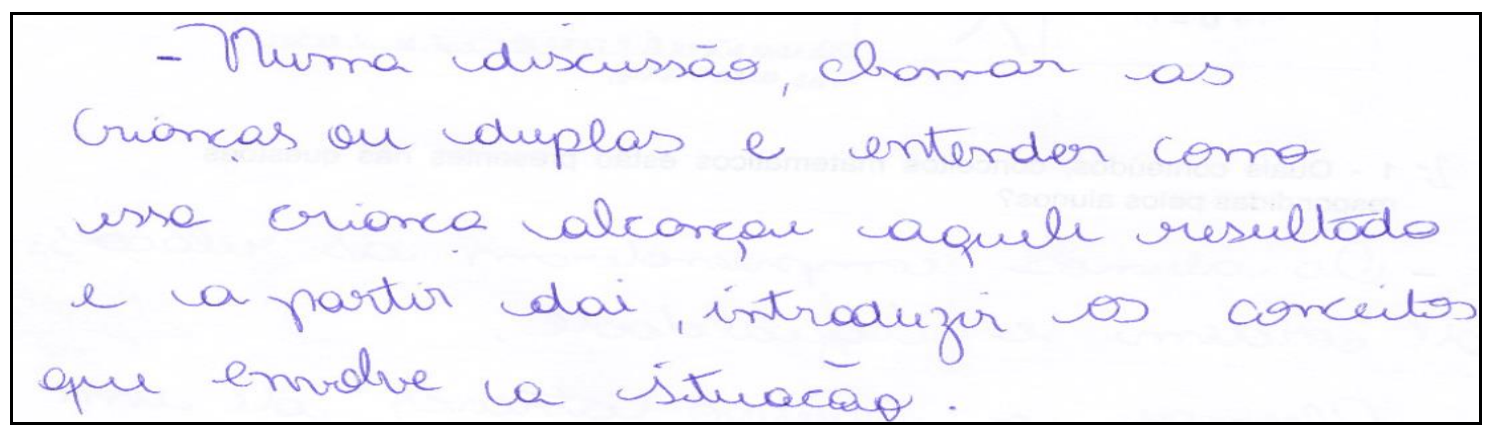

Figura 8 - Questionamento aos alunos

Fonte: Protocolo de Pesquisa

Essa resposta associa-se ao que se pode considerar um ouvir sem escutar, pois a informação que o aluno vai fornecer servirá apenas como lançamento para que o professor possa "introduzir os conceitos envolvidos" e, assim, mostrar a "forma correta de responder" (Ribeiro et al., 2016). Para Franke, Carpenter e Battey (2008), os professores, na intenção de efetivar um trabalho mais voltado para o desenvolvimento do Pensamento Algébrico, em vez de perguntar aos alunos: "Como você resolveu o problema?", deveriam perguntar: "Isso vai funcionar para todos os números ou todas as operações?”, questão que permite direcionar a busca das regularidades e das generalizações. 


\section{Considerações finais}

Neste trabalho procuramos aprofundar o nosso entendimento sobre o conhecimento matemático para ensinar, revelado por um grupo de professores dos Anos Iniciais, ao discutir tarefas com potencial algébrico. Os resultados indicam, na generalidade, uma reduzida familiaridade dos participantes com os aspectos vinculados ao Pensamento Algébrico associado a um conhecimento matemático para ensinar, sustentado ainda, essencialmente, em aspectos do CCK.

No que se refere aos diferentes significados do sinal de igual (por exemplo, $24+37$ $=37+24$ ), a discussão, a partir da análise de um dos protocolos dos alunos, contribuiu para uma toma de consciência relativamente a quanto o ensino (aqui, em concreto, com um foco nos Anos Iniciais) enfatiza o sinal de igual na perspectiva do seu significado operacional, a partir de uma estrutura basicamente aritmética, objetivando a fluência do cálculo. No entanto, essa tomada de consciência não contribuiu, em si, à emergência de uma justificativa que tivesse por base o fazer matemático (SCK), o que nos leva a equacionar também a necessidade de uma alteração de foco na própria formação - em termos do que se discute e dos objetivos dessa discussão - de modo a desenvolver um conhecimento que possibilite atribuir sentido e significado às respostas dos alunos (Ribeiro et al., 2016), e investir nas diversas dimensões do seu Pensamento Algébrico.

Com relação às propriedades das operações, as discussões revelaram um conhecimento mais de um nível do CCK do que um conhecimento que explicitasse os porquês matemáticos (SCK) ou a simples preocupação em buscar essas explicitações. Isso indica também a necessidade de que a formação tenha por objetivo último o desenvolvimento desse conhecimento. E, ao mesmo tempo, revela potencialidades do trabalho de formação. No entanto, a partir das discussões ocorridas não nos foi possível averiguar um conhecimento que fosse muito além do saber fazer ou saber identificar o erro dos alunos (CCK), ainda que a natureza da tarefa proposta propiciasse isso (e.g., Jakobsen et al., 2014).

Pesquisas têm demonstrado que o desenvolvimento do Pensamento Algébrico nos alunos requer que o professor prepare e implemente tarefas com objetivo de discutir, argumentar e comparar ideias matemáticas, além de buscar generalizações a partir de tarefas advindas da própria Aritmética (Canavarro, 2007; Russell et al., 2011). Porém, desenvolver tais atividades, coordenar debates nos quais os alunos explicitem suas ideias matemáticas, explorar qualquer oportunidade que surja em sala de aula para rever ou aprofundar conceitos matemáticos, depende em grande parte da profunda compreensão dos conceitos matemáticos pelo próprio professor, segundo explicita Ma 2009). De fato, como nos alertam Fiorentini et al. (2005), não se trata de tarefas específicas para o desenvolvimento do Pensamento Algébrico, mas, antes, de tarefas com potencial algébrico, potencialidade essa que cabe ao professor, por meio de seu conhecimento matemático, fomentar. Torna-se, portanto, essencial a melhoria da qualidade do conhecimento do professor, pois só assim será possível melhorar a educação matemática dos alunos (Ma, 2009). 
Nesse sentido, ganha corpo a necessidade de maiores (em termos de amplitude) e mais aprofundados estudos, a fim de ampliar o entendimento do conhecimento matemático para ensinar do professor e possibilitar a integração entre a Aritmética ensinada nos Anos Iniciais do Ensino Fundamental e a Álgebra ainda apresentada e explorada somente a partir dos Anos Finais. Nesse processo de integração e de desenvolvimento do Pensamento Algébrico, não consideramos a necessidade de um acréscimo de conteúdos ao currículo, mas, sim, uma reformulação, em termos de foco e de objetivos associados às práticas - o que implica, necessariamente, uma reformulação na própria formação inicial e continuada.

Essa mudança de foco associa-se à perseguição de objetivos a médio e longo prazo, e não apenas imediatos (mas também esses), o que implica possibilitar e potenciar deixar a porta aberta para futuras aprendizagens - incrementando a qualidade das discussões matemáticas. Com essa perspectiva torna-se viável uma perspectiva de trabalho com o Pensamento Algébrico, de forma a ir além do trabalho com os algoritmos e desviando o foco na técnica operatória e na busca do resultado final.

\section{Referências}

Amaral, R. B., Ribeiro, M., \& Godoy J. S. (2014). Choosing textbooks without looking at the textbooks - the role of the other's interpretations. In International conference on mathematics textbook research and development (ICMT) (pp. 29-31). University of Southampton, UK.

Ball, D., Thames, M. H., \& Phelps, G. (2008). Content knowledge for teaching: what makes it special? Journal of Teacher Education, 59(5), 389-407.

Blanton, M. et al. (2011). Developing essential understanding of algebraic thinking for teaching Mathematics in grades 3-5. Reston,Va: NCTM - National Council Teachers of Mathematics.

Blanton, M. L., \& Kaput, J. J. (2004). Elementary grade students' capacity for functional thinking. In M. J. Høines, \& A. B. Fuglestad (Eds.), Proceedings of the 28th Conference of the International Group for the Psychology of Mathematics Education (Vol. 2, pp. 135-42). Bergen, Norway: PME.

Blanton, M., \& Kaput, J. (2005). Characterizing a classroom practice that promotes algebraic reasoning. Journal for Research in Mathematics Education, 36(5), 412-446.

Brasil. Ministério da Educação. Secretaria de Educação Fundamental. Parâmetros Curriculares Nacionais: Matemática. Brasília: MEC/SEF, 1997.

Cai, J., \& Knuth, E. (Eds.). (2011). Early algebraization. New York: Springer.

Canavarro, A. P. (2007). O pensamento algébrico na aprendizagem da Matemática nos primeiros anos. Quadrante, Lisboa-PT, 16(2), 81-118. 
DOI: http://dx.doi.org/10.20396/zet.v25i3.8648585

Carpenter, T. P., Franke, M. L., \& Levi, L. (2003). Thinking mathematically:Integrating arithmetic and algebra in elementary school. Portsmouth, NH: Heinemann.

Carraher, D. W., Schliemann, A. D., Brizuela, B. M., \& Earnest, D. (2006). Arithmetic and algebra in early Mathematics Education. Journal for Research in Mathematics Education, 2(37), 87-115.

Ferreira, M. C. N. (2017a). Álgebra nos Anos Iniciais do Ensino Fundamental: uma análise do conhecimento matemático acerca do Pensamento Algébrico. Dissertação de Mestrado. Universidade Federal do ABC.

Ferreira, M. C. N. (2017b) (no prelo). Álgebra nos Anos Iniciais do Ensino Fundamental: uma análise dos documentos curriculares nacionais.

Ferreira, M. C. N, Ribeiro, A. J., \& Ribeiro, M. (2017) (no prelo). Álgebra nos Anos Iniciais do Ensino Fundamental: investigando a compreensão dos professores acerca do Pensamento Algébrico.

Fiorentini, D., Fernandes, F. L. P., \& Cristóvão, E. M. (2005). Um Estudo das Potencialidades pedagógicas das investigações Matemáticas no desenvolvimento do pensamento algébrico. In: Seminário Luso-Brasileiro de Investigações Matemáticas no Currículo. Portugal. Retirado em 26 de maio, 2015, de: http://www.educ.fc.ul.pt/docentes/jponte/seminario_lb.htm.

Franke, M., Carpenter, T. P., \& Battey, D. (2008). In J. J. Kaput, D. W. Carraher, \& M. L. Blanton (Eds.), Algebra in the early grades (pp. 333-360). New York: Routledge.

Jakobsen, A., Ribeiro, C. M., \& Mellone, M. (2014). Norwegian prospective teachers' MKT when interpreting pupils' productions on a fraction task. Nordic Studies in Mathematics Education, 19(3-4), 135-150.

Jakobsen, A., Thames, M., \& Ribeiro, C. M. (2013). Delineating issues related to Horizon Content Knowledge for mathematics teaching. In B. Ubuz, Ç. Haser \& M. A. Mariotti (Eds.), Proceedings of CERME 8 (pp. 3125-3134). Antalia, Turkie: ERME.

Kieran, C. (1992). The learning and teaching of school algebra. In D. A. Grouws (Ed.), Handbook of research on mathematics teaching and learning (pp. 390-419). New York: Macmillan.

Kieran, C. (2004). Algebraic thinking in the early grades: What is it? The Mathematics Educator, Georgia, 8(1), 139-151.

Kieran, C., Pang, J. S., Schifter, D., \& Ng, S. F. (2016). Early Algebra. In ICME-13Topical Surveys, Hamburg.

Krauss, S., Baumert, J., \& Blum, W. (2008). Secondary mathematics teachers' pedagogical content knowledge and content knowledge: validation of the COACTIV constructs. ZDM, 40(5), 873-892. 
Linchevski, L. (1995). Algebra with numbers and arithmetic with letters: A definition of prealgebra. Journal of Mathematical Behavior, (14), 113-120.

Lins, R. C., \& Gimenez, J. (2001). Perspectivas em aritmética e álgebra para o século XXI. Campinas, SP: Papirus.

Ma, L. (2009). Saber e ensinar: Matemática elementar. Lisboa: Gradiva.

Mason, J., Graham, A., \& Johnston-Wilder, S. (2005). Developing thinking in algebra. London: Sage.

Mestre, C., \& Oliveira, H. (2011). O pensamento algébrico e a capacidade de generalização de alunos do $3 .^{\circ}$ ano de escolaridade do ensino básico. In C. Guimarães, \& P. Reis, (Orgs.), Professores e infâncias: estudos e experiências (pp. 201-223). São Paulo: Junqueira \& Marin.

Molina, M. (2009). Una propuesta de cambio curricular: integración del pensamiento algebraico en educación primaria. PNA, 3(3), 135-156.

Nye, B., Konstantopoulos, S., \& Hedges, L. V. (2004). How large are teacher effects? Educational Evaluation and Policy Analysis, 26(3), 237-257.

Ponte, J., Branco, N., \& Matos, A. (2009). Álgebra no Ensino Básico. Portugal: Ministério da Educação, Direção Geral de Integração e de Desenvolvimento Curricular (DGIDC).

Ribeiro, M., Mellone, M., \& Jakobsen, A. (2016). Interpreting students' non standard reasoning: Insights for mathematics teacher education practices. For the Learning of Mathematics, 36(2), 8-13.

Russell, S. J., Schifter, D., \& Bastable, V. (2011). Developing algebraic thinking in the context of arithmetic. In J. Cai, \& E. Knuth (Ed.), Early algebraization (pp. 43-69, Coleção Advances in Mathematics Education). Berlin: Springer-Verlag Heidelberg.

Schliemann, A. D., Carraher, D. W., \& Brizuela, B. M. (2007). Bringing out the algebraic character of arithmetic: From children's ideas to classroom practice. Mahwah, New Jersey: Lawrence Erlbaum Associates.

Shulman, L. S. (1986). Those who understand: Knowledge growth in teaching. Educational Researcher, 15(2), 4-14.

Silva, T. H. I., \& Ribeiro, A. J. (2014). O sinal de igualdade e seus diferentes significados: buscando rupturas na transição entre os Ensinos Fundamental I e II. REnCiMa, 5(2), 75-90.

Trivilin, L. R., \& Ribeiro, A. (2015). Conhecimento matemático para o ensino de diferentes significados do sinal de igualdade: um estudo desenvolvido com professores dos Anos Iniciais do Ensino Fundamental. Bolema, 29(51), 38-59. 
DOI: http://dx.doi.org/10.20396/zet.v25i3.8648585

Wasserman, N.H. (2016). Abstract algebra for algebra teaching: Influencing school mathematics instruction. Canadian Journal of Science, Mathematics and Technology Education, 16(1), 28-47. 